University of Nebraska - Lincoln

DigitalCommons@University of Nebraska - Lincoln

$6-23-2006$

\title{
Sensitivity of the Anxiety Disorder Interview Schedule IV in Detecting Potentially Traumatic Childhood Maltreatment
}

\author{
David DiLillo \\ University of Nebraska-Lincoln, ddilillo@unl.edu \\ Sarah A. Hayes \\ University of Nebraska-Lincoln \\ Debra A. Hope \\ University of Nebraska-Lincoln, dhope1@unl.edu
}

Follow this and additional works at: https://digitalcommons.unl.edu/psychfacpub

Part of the Psychiatry and Psychology Commons

DiLillo, David; Hayes, Sarah A.; and Hope, Debra A., "Sensitivity of the Anxiety Disorder Interview Schedule IV in Detecting Potentially Traumatic Childhood Maltreatment" (2006). Faculty Publications, Department of Psychology. 123.

https://digitalcommons.unl.edu/psychfacpub/123

This Article is brought to you for free and open access by the Psychology, Department of at DigitalCommons@University of Nebraska - Lincoln. It has been accepted for inclusion in Faculty Publications, Department of Psychology by an authorized administrator of DigitalCommons@University of Nebraska - Lincoln. 


\title{
Sensitivity of the Anxiety Disorder Interview Schedule IV in Detecting Potentially Traumatic Childhood Maltreatment
}

\author{
David DiLillo,* Sarah A. Hayes, and Debra A. Hope \\ Department of Psychology, University of Nebraska-Lincoln \\ *Corresponding author: 238 Burnett Hall, Lincoln, Nebraska 68588; e-mail: ddilillo@unl.edu.
}

Accepted July 1, 2005

\begin{abstract}
This study examined the sensitivity of the Anxiety Disorder Interview Schedule IV (ADIS-IV) in detecting potentially traumatic childhood abuse experiences in a sample of 50 consecutive adult anxiety disorder patients. Of 13 patients who reported traumatic childhood maltreatment experiences using a behaviorally specific abuse history questionnaire, seven failed to report these experiences during the ADIS-IV interview (a sensitivity of 46\%). Findings suggest that the two omnibus gating questions on the ADIS-IV may be insufficient in capturing exposure to certain traumatic events, as stipulated by Diagnostic and Statistical Manual diagnostic criteria for a diagnosis of post-traumatic stress disorder (PTSD). This potential for under identification of trauma history suggests that caution is warranted regarding the use of the ADIS-IV to screen for self-reported trauma exposure in adult outpatients. Alternatives, including the use of PTSD-specific interviews and supplemental trauma event checklists, are discussed.
\end{abstract}

KEY WORDS: ADIS-IV; PTSD; trauma; child maltreatment.

Unlike most psychological disorders, the diagnosis of post-traumatic stress disorder (PTSD) involves a clear, definable precipitating incident. According to the fourth edition of the Diagnostic and Statistical Manual of Mental Disorders (DSM-IV-TR; American Psychiatric Association, 2000), a diagnosis of PTSD must meet the following criteria: (A1) exposure to a traumatic event that involves actual or threatened death or serious injury, or a threat to the physical integrity of oneself or another person, and (A2) a personal response to such an event that involves intense fear, helplessness, or horror. Failure to meet either of these criteria rules out a diagnosis of PTSD and precludes the assessment of other PTSD-related diagnostic criteria, such as the presence of re-experiencing, avoidance behaviors, and hyperarousal.

Structured and semi-structured interviews are widely used in both clinical and research settings and have been shown to improve the reliability and validity of psychiatric diagnoses in comparison with unstructured interview methods (Helzer, Robins, Croughan, \& Welner, 1981; Spitzer, Williams, Gibbon, \& First, 1992; Wrighte, Lichtenfels, \& Pursell, 1989). One popular structured interview, the Anxiety Disorder Inter- view Schedule for DSM-IV (ADIS-IV; Brown, Di Nardo, \& Barlow, 1994) is specifically designed to provide diagnoses for a range of anxiety, mood, and somatoform disorders, based on the Diagnostic and Statistical Manual (DSM-IV; American Psychiatric Association, 1994). Various versions of the ADIS have been used in over 150 published articles, and multiple studies have supported the psychometric properties of the ADIS-IV in accurately classifying a range of anxiety-related disorders (see Brown \& Barlow, 2001).

The ADIS-IV utilizes a branching format that includes gating (i.e., screening) questions for each diagnostic category. Responses to these questions determine whether more specific, symptom-related inquiries necessary to confirm a diagnosis should be asked. In the case of PTSD, two gating questions are asked: (1) "Have you ever experienced or witnessed a traumatic or life-threatening event such as assault, rape, seeing someone badly injured or killed, combat, accidents, or natural or man-made disasters?" and (2) "Do you recall any events of this nature occurring when you were a child?" The goal of these questions, which correspond roughly to DSM criterion A1 noted above, is to detect the presence of any traumatic event that respondents 
may have experienced. An affirmative response to either gating question is followed by more specific queries regarding the various symptom clusters associated with PTSD. However, if neither question elicits an affirmative response, then the follow-up questions required for a diagnosis of PTSD are not asked. ${ }^{1}$

Clearly, the PTSD gating questions on the ADISIV play a pivotal role in determining whether an individual can be diagnosed with PTSD. To the degree that these questions produce false-negative responses (i.e., those in which a respondent fails to report a traumatic event that actually occurred), PTSD may be under diagnosed using the ADIS-IV. To date, however, the sensitivity of these questions in detecting a history of trauma exposure has yet to be evaluated. This is concerning considering that another common semi-structured diagnostic interview, the Structured Clinical Interview for (SCID; Spitzer et al., 1992), which uses similar screening questions to assess trauma history, has been shown to under diagnose PTSD (Franklin, Sheeran, \& Zimmerman, 2002).

The purpose of this study is to provide initial information regarding the sensitivity of the ADIS-IV PTSD gating questions in identifying a specific class of traumatic events - those related to childhood maltreatment (physical abuse, childhood sexual abuse, and witnessing domestic violence). The accurate detection of these childhood experiences is important for each of these events has been linked to the development of acute, chronic, and delayed onset PTSD (cf. Lehmann, 2000; Malinosky-Rummell \& Hansen, 1993; Polusny \& Follette, 1995). To evaluate the sensitivity of the ADIS-IV in detecting abuse-related trauma, participants were administered the ADIS-IV interview in addition to a behaviorally specific questionnaire assessing childhood abuse experiences that are potential precipitants of PTSD. In contrast to omnibus screening questions, behaviorally descriptive items focus on particular types of events, often using multiple questions for each traumatic experience (e.g., sexual abuse, physical abuse, and exposure to domestic violence). Most importantly, behaviorally specific questions operationalize traumatic events in objective terms and therefore may be more

\footnotetext{
${ }^{1}$ Another complicating factor comes from possible ambiguity regarding the proper use of the two screener questions ("Have you ever experienced or witnessed a traumatic or life-threatening event such as assault, rape, seeing someone badly injured or killed, combat, accidents, or natural or man-made disasters?" and "Do you recall any events of this nature occurring when you were a child?"). These questions appear consecutively, with no specific interviewer instructions provided. Given that the first question asks whether a respondent has ever experienced a traumatic event, it remains unclear whether both questions should be asked of all respondents.
}

sensitive in detecting exposure to the traumatic experiences (Weaver, 1998).

\section{METHOD}

\section{Participants}

Participants were 50 consecutive clients with an ADIS-IV Clinical Severity Rating (CSR) of 4 or greater who were treated at the Anxiety Disorders Clinic (ADC) at the University of Nebraska-Lincoln. A CSR in this range indicates clinical severity and moderate impairment in daily functioning. Participants learned about the ADC from several referral sources including print advertisements, word of mouth, local physicians, and mental health professionals. Referrals cover all anxiety disorders, however, in this sample, primary diagnoses included social anxiety disorder $(n=16)$, panic disorder $(n=14)$, generalized anxiety disorder $(n=$ $9)$, specific phobia $(n=3)$, obsessive-compulsive disorder $(n=2)$, major depressive disorder $(n=2)$, PTSD $(n=1)$, adjustment disorder with anxiety $(n=1)$, obsessive-compulsive personality disorder $(n=1)$, and dysthymia $(n=1)$. In addition, 26 individuals also received at least one additional clinically significant comorbid diagnosis, as indicated by a CSR of 4 or greater. Of interest for this article is one individual who had a clinically significant comorbid diagnosis of PTSD. All participants had a mean age of 42.6 years $(S D=$ 16.3 ; range $=19-81) ; 60 \%$ were female; $98 \%$ Caucasian; $44 \%$ married; and $42 \%$ college graduates.

\section{Measures}

\section{Anxiety Disorders Interview Schedule for DSM-IV (ADIS-IV; Brown et al., 1994)}

The ADIS-IV is designed to assess the presence of anxiety disorders based on DSM-IV criteria. In addition to assessing anxiety disorders, the ADIS-IV also contains sections on mood, somatoform, and substance use disorders as well as brief screening items for psychotic and conversion symptoms. The ADIS-IV is designed to yield a five-axis diagnosis (Brown et al., 1994).

The ADIS-IV has demonstrated good-to-excellent interrater reliability with kappa coefficients ranging from .67 to .86 for the various anxiety disorders. However, the sample size for individuals with a primary diagnosis of PTSD was too small to calculate a kappa coefficient (Brown, Di Nardo, Lehman, \& Campbell, 2001). An early version of the ADIS, the ADIS-R, demonstrated moderate interrater reliability $(k=.46)$ for individuals with a primary diagnosis of PTSD. However, there were only three individuals 
in this sample (Di Nardo, Moras, Barlow, Rapee, \& Brown, 1993).

\section{Comprehensive Child Maltreatment Scale for Adults} (CCMS; Higgins \& McCabe, 2001)

The Comprehensive Child Maltreatment Scale for Adults (CCMS) is a 22-item paper-and-pencil questionnaire designed to assess retrospectively five major forms of childhood maltreatment including sexual abuse, physical abuse, psychological abuse, neglect, and witnessing domestic violence (Higgins \& McCabe, 2001). The CCMS uses behaviorally specific criteria to elicit reports of the frequency of behaviors that respondents were subjected to as a child. Items are rated on a 5-point Likert scale ranging from 0-Never or Almost Never to 4-Very Frequently. Participants respond to each behaviorally specific item in reference to three potential perpetrators: the participant's mother, the participant's father, and another older adult or adolescent who was at least 5 years older than the participant. Table I shows the items from the CCMS that were considered to be potentially traumatic in this study.

Higgins and McCabe (2001) report that the CCMS has demonstrated strong internal consistency; coefficient alpha for the total CCMS was .92-.93. Coefficient alphas for individual scales used in the present study have been reported as .88 for sexual abuse, .66-.76 for physical abuse, and .77-.83 for witnessing family violence (Higgins \& McCabe, 2001). In this sample, coefficient alpha was .89 for the total CCMS, .84 for sexual abuse, and .62 for physical abuse (only a single item from the witnessing scale was used here). In addition, 6-to 8-week test-retest reliability has been reported as adequate to excellent for sexual abuse $(r=$ $.95)$, physical abuse $(r=.87)$,

witnessing family violence $(r=.77)$, and overall $(r=$ .92; Higgins \& McCabe, 2001). Scales on the CCMS correlate with similar scales on the Child Abuse and
Trauma scale (CAT; Sanders \& Becker-Lausen, 1995) providing evidence of concurrent criterion-related validity (Higgins \& McCabe, 2001). The sexual abuse scale on the CCMS, for example, was strongly correlated with the CAT sexual abuse scale $(r=.87)$.

\section{Procedure}

After a phone screen to ascertain whether callers were experiencing problematic anxiety for which they were not being treated elsewhere, participants came to the clinic and were administered the ADIS-IV by a licensed clinical psychologist or one of five advanced doctoral students who had completed extensive training. Training consisted of observing three ADIS-IVs conducted by an experienced interviewer then conducting at least five interviews under observation. Trainees were required to match the experienced interviewer on four of five interviews. For a match, both interviewers must score within one point of the $0-8 \mathrm{CSR}$ scale for the primary diagnosis and identify all secondary diagnoses of clinical severity. As noted, individuals with an ADIS-IV CSR of 4 or greater were included in the present study. Primary diagnosis is defined as the highest CSR. All ADIS-IV interviews and diagnostic decisions were presented and reviewed at weekly staff meetings.

All new clients were administered the CCMS during the assessment phase before treatment began. A small number of clients who were already in treatment at the beginning of this study were administered the CCMS after treatment began. All participants gave separate informed consent for the ADIS interview and completion of the CCMS. All participants were informed that completion of the CCMS was optional (a total of three refused). This study was approved by the University of Nebraska-Lincoln Institutional Review Board.

Table I. Items From the CCMS Representing Potentially Traumatic Childhood Experiences

\begin{tabular}{ll}
\hline \multicolumn{1}{c}{ Category } & \multicolumn{1}{c}{ Item } \\
\hline Sexual abuse $^{a}$ & Adult sometimes touched your penis, vagina, or breasts \\
& Adult sometimes made you touch his penis/her vagina or breasts \\
& Adult occasionally made you put your mouth on his penis/her vagina \\
& Adult occasionally put his penis in your vagina or anus \\
& Adult occasionally put a finger in your vagina or anus \\
Physical abuse & Frequent use of other violence (e.g., hitting, punching, kicking) by a parent or adult other against the victim \\
Witnessing violence & Frequently witnessed physical aggression toward others in the family \\
\hline
\end{tabular}

${ }^{a}$ Acts occurring before the victim was 13 years of age, with someone at least 5 years older than the victim. 


\section{RESULTS}

\section{Traumatic Experiences Reported on the ADIS-IV}

Of the 50 total participants, 27 responded negatively to both ADIS-IV screeners, while 23 responded affirmatively to at least one of the two gating questions on the PTSD section of the ADIS-IV. Five of the 23 individuals reported child abuse-related events on the ADIS-IV, which could have been detected on the CCMS; these include childhood sexual abuse $(n=2)$ and physical violence in the home $(n=3)$. Of these five individuals, four reported similar experiences on the CCMS, while one (a physical abuse case) did not. Thus, the CCMS "captured" all but one child abuse-related trauma that was detected with the ADIS-IV. The other traumatic events reported by the remaining 18 individuals on the ADIS-IV, which were not assessed on the CCMS, included accident-related traumas $(n=10)$, death-or health-related traumas $(n=5)$, non-abuse-related trauma in adulthood $(n=2)$, and combat $(n=1)$.

\section{Traumatic Experiences Reported on the CCMS}

A total of 13 participants were classified as experiencing a potentially traumatic abuse-related event based on the CCMS. These participants endorsed experiences of sexual abuse including physical contact or penetration of respondent's vagina or anus by an adult ( $n$ $=2$ ), physical abuse that included frequently being hit, punched, or kicked by an adult $(n=7)$, and witnessing domestic violence that involved observing physical aggression by an adult toward other family members ( $n=$ 6 ). Two individuals endorsed both physical abuse and witnessing domestic violence items.

\section{Sensitivity of the ADIS-IV PTSD Gating Questions}

Of the 27 participants who responded negatively to both PTSD gating questions on the ADIS-IV, seven $(26 \%)$ endorsed at least one item on the CCMS that indicated a potentially traumatic event. This means that $54 \%$ (7/13) of the individuals who reported potentially traumatic events on the CCMS were not identified by the ADIS-IV. Thus, the sensitivity of the ADIS-IV in detecting potentially traumatic forms of childhood maltreatment was determined to be $46 \%$ (6/13 individuals identified). Of the seven individuals who reported abuse on the CCMS, but not on the ADIS-IV, five reported physical abuse and three reported witnessing family violence. One person reported both physical abuse and witnessing family violence on the CCMS, but not on the ADIS-IV.

\section{DISCUSSION}

This study evaluated the sensitivity of the ADISIV in identifying three specific types of early life trauma: physical abuse, sexual abuse, and witnessing domestic violence. Results indicate that childhood maltreatment (particularly physical abuse and exposure to domestic violence) may be underreported on the ADISIV interview. More specifically, findings suggest that compared to reports obtained with the CCMS, a wellvalidated abuse history measure, the two gating questions on the ADIS-IV may lack the sensitivity required to capture certain childhood events that are potential precursors to adult PTSD. One question raised by these findings is whether this underreporting of traumatic child abuse could ultimately lead to an under diagnosis of PTSD using the ADIS-IV. While this possibility was not tested here, Franklin and colleagues (2002) reported that $10 \%$ of patients responding negatively to SCID trauma screeners were later found to meet diagnostic criteria for PTSD. This finding, in combination with results from the current study, highlights the need for future investigations to evaluate the accuracy of the ADIS-IV in diagnosing PTSD.

One factor that could contribute to the low sensitivity observed here is the general nature of the two ADISIV screening questions. These broadly structured queries may be inadequate to prompt recall of early abuse and exposure to parental violence, a common childhood precipitant of PTSD. This possibility is consistent with other research on PTSD gating questions, which has revealed that omnibus questions are less effective than trauma checklists in assessing lifetime trauma exposure (Goodman, Corcoran, Turner, Yuan, $\&$ Green, 1998). The present results are also congruent with data showing that assessment instruments that operationalize traumatic events in behaviorally specific terms yield increased reporting of such experiences (Weaver, 1998).

Although the present findings are revealing, limitations of the current study suggest several directions for future research. First, the accuracy of the ADIS-IV in actually diagnosing PTSD was not examined. Future investigations could address this issue by evaluating PTSD symptomatology in individuals who respond negatively to the ADIS-IV screeners, but who report trauma exposure on a more thorough screening instrument. Relatedly, direct questioning of respondents regarding their perceptions of the ADIS-IV screeners in comparison with behaviorally specific measures could reveal useful information about the limitations of omnibus questions. Secondly, the relatively small number of abuse victims in this sample is a limitation. For example, although both the individuals who reported sex- 
ual abuse on the CCMS also reported this experience on the ADIS-IV, it is unclear whether the ADIS-IV would reliably detect sexual abuse in a larger sample of victims. Thirdly, the present study evaluated the sensitivity of the ADIS-IV in detecting exposure to only a small range of traumatic events (i.e., childhood maltreatment). However, the finding that only one of 23 participants who screened positive for trauma exposure was ultimately diagnosed with PTSD also raises questions about the specificity of the gating questions in detecting non-abuse traumas. Finally, research is needed to evaluate the ADIS-IV screening questions in an unbiased fashion (i.e., free from possible priming or pretest sensitization). Here, measures were administered in a fixed order, with the ADIS-IV preceding the CCMS. Because of the time period between the two measures (one to two weeks) and the fact that ADIS-IV screeners were embedded within a large assessment battery, it seems unlikely that responses on the CCMS would be impacted by prior administration of the ADIS-IV. Nevertheless, randomizing the presentation of measures would be required to definitively rule out order effects.

Limitations notwithstanding, this study has implications for those working with PTSD populations. Clinicians and researchers should be aware that the current ADISIV screeners may not detect exposure to certain traumatic events. Those interested primarily in the assessment of PTSD might consider using one of several psychometrically sound structured interviews designed specifically for that purpose, such as the Clinician-Administered PTSD scale (Blake et al., 1995). Alternatively, ADIS-IV users may wish to supplement its omnibus screeners with behaviorally specific questions to more comprehensively assess trauma exposure. Brief stand-alone checklists, which use separate questions to inquire about a range of traumatic events, including childhood abuse, may be useful in this regard. Examples of such checklists include the Trauma History Questionnaire (Green, 1996), the Potential Stressful Events Interview (Resnick, Falsetti, Kilpatrick, \& Freedy, 1996), and the Stressful Life Events Screening Questionnaire (Goodman et al., 1998).

\section{REFERENCES}

American Psychiatric Association. (1994). Diagnostic and statistical manual of mental disorders (4th ed.). Washington, DC: Author.

American Psychiatric Association. (2000). Diagnostic and statistical manual of mental disorders (4th ed., text revision). Washington, DC: Author.

Blake, D. D., Weathers, F. W., Nagy, L. M., Kaloupek, D. G., Gusman, F. D., Charney, D. S., \& Keane, T. M. (1995). The development of a clinician-administrated PTSD scale. Journal of Trauma Stress, 8, 75-90.
Brown, T. A. \& Barlow, D. H. (2001). Classification of anxiety and mood disorders. In Anxiety and its disorders: The nature and treatment of anxiety and panic (2nd ed., pp. 292-327). New York: Guilford Press.

Brown, T. A., Di Nardo, P. A., \& Barlow, D. H. (1994). Anxiety Disorders Interview Schedule for DSM-IV (ADIS-IV). San Antonio, TX: Psychological Corporation/Graywind Publications Incorporated.

Brown, T. A., Di Nardo, P. A., Lehman, C. L., \& Campbell, L. A. (2001). Reliability of DSM-IV anxiety and mood disorders: Implications for classification of emotional disorders. Journal of Abnormal Psychology, 110, 49-58.

Di Nardo, P. A., Moras, K., Barlow, D. H., Rapee, R. M., \& Brown, T. A. (1993). Reliability of the DSM-III-R anxiety disorder categories using the Anxiety Disorders Interview Schedule-Revised (ADIS-R). Archives of General Psychiatry, 50, 251-256.

Franklin, A. L., Sheeran, T., \& Zimmerman, M. (2002). Screening for trauma histories, posttraumatic stress disorder (PTSD), and subthreshold PTSD in psychiatric outpatients. Psychological Assessment, 14, 467-472.

Goodman, L. A., Corcoran, C., Turner, K., Yuan, N., \& Green, B. L. (1998). Assessing traumatic event exposure: General issues and findings for the Stressful Life Events Screening Questionnaire. Journal of Traumatic Stress, 11, 521- 542.

Green, B. L. (1996). Trauma history questionnaire. In B. H. Stamm (Ed.), Measurement of stress, trauma, and adaptation (pp. 366369). Lutherville, MD: Sidran Press.

Helzer, J. E., Robins, L. N., Croughan, J. L., \& Welner, A. (1981) Renard diagnostic interview. Its reliability and procedural validity with physicians and lay interviewers. Archives of General Psychiatry, 38, 393-398.

Higgins, D. J., \& McCabe, M. P. (2001). The development of the Comprehensive Child Maltreatment Scale. Journal of Family Studies, 7, 7-28.

Lehmann, P. (2000). Posttraumatic stress disorder (PTSD) and child witnesses to mother-assault: A summary and review. Children and Youth Services Review, 22, 275-306.

Malinosky-Rummell, R. \& Hansen, D. J. (1993). Long-term consequences of childhood physical abuse. Psychological Bulletin, $114,68-79$.

Polusny, M. M., \& Follette, V. M. (1995). Long-term correlates of childhood sexual abuse: Theory and empirical findings. Applied and Preventive Psychology, 4, 143-166.

Resnick, H. S., Falsetti, S. A., Kilpatrick, D. G., \& Freedy, J. R. (1996). Assessment of rape and other civilian trauma-related post-traumatic stress disorder: Emphasis on assessment of potentially traumatic events. In T. W. Miller (Ed.), Stressful life events (pp. 231-266). Madison: International Universities Press.

Sanders, B., \& Becker-Lausen, E. (1995). The measurement of psychological maltreatment: Early data on the child abuse and trauma scale. Child Abuse and Neglect, 19, 315-323.

Spitzer, R. L., Williams, J. B. W., Gibbon, M., \& First, M. B. (1992). The Structured Clinical Interview for DSM-III-R: I. History, rationale and description. Archives of General Psychiatry, 49, 624629.

Weaver, T. L. (1998). Method variance and sensitivity screening for traumatic stressors. Journal of Traumatic Stress, 11, 181-185.

Wrighte, P. M., Lichtenfels, P. A., \& Pursell, E. D. (1989). The structured interview: Additional studies and a meta-analysis. Journal of Occupational Psychology, 62, 191-200. 